\title{
Finite Element Analysis of the Effect of Internal Pressure on Orifice Flowmeter
}

\author{
Lianghuai Tong ${ }^{1}$, Sulu Zheng ${ }^{1,}$, , Xiuqin Chen ${ }^{2}$, Jian Fan $^{2}$, Shuyuan Wang ${ }^{2}$, Jinfu Li $^{2}$ \\ ${ }^{1}$ Quzhou Special Equipment Inspection Center, Quzhou, China \\ ${ }^{2}$ College of Mechanical Engineering, Quzhou University, Quzhou, China
}

Email address:

zhang002@sina.com (Sulu Zheng)

${ }^{*}$ Corresponding author

\section{To cite this article:}

Lianghuai Tong, Sulu Zheng, Xiuqin Chen, Jian Fan, Shuyuan Wang, Jinfu Li. Finite Element Analysis of the Effect of Internal Pressure on Orifice Flowmeter. American Journal of Mechanical and Industrial Engineering. Vol. 4, No. 4, 2019, pp. 52-63.

doi: 10.11648/j.ajmie.20190404.11

Received: September 20, 2019; Accepted: October 7, 2019; Published: October 20, 2019

\begin{abstract}
The flow rate in a closed pipe is a dynamic value, the instrument for measuring the flow rate is called a flowmeter. Typical flowmeters are: differential pressure flowmeter, electromagnetic flowmeter, coriolis mass flowmeter, vortex flowmeter, ultrasonic flowmeter, etc. Among them, differential pressure flowmeter, represented by orifice flowmeter, is the mainstream flowmeter applied at home and abroad. Orifice flowmeter has the advantages of simple structure, low cost and stable performance, it is widely used in chemical industry, electric power, heating, water supply and other fields, and can be used to measure the flow of different media. When the fluid filled with pipeline flows through the orifice plate, it will produce local contraction, concentration of flow beam, increase of flow velocity, and decrease of static pressure, so there will be a static pressure difference before and after the orifice plate. The orifice flowmeter is equipped with an orifice plate on the pipeline, and the orifice plate is connected with pressure measuring tubes on both sides, and they are respectively connected with a U-type pressure differential meter. Orifice flowmeter uses the throttling effect of fluid through the sharp hole to increase the flow velocity and decrease the pressure, resulting in the pressure difference between front and back orifice plates, as the basis of measurement. In this paper, to study the influence of different pressure loads on the accuracy of the orifice flowmeter, the mathematical model is established by simulation software, and the different pressure loads of the orifice flowmeter are analyzed under the temperature load of $20^{\circ} \mathrm{C}$. The results show that the location of the orifice flowmeter under the maximum stress, maximum displacement and maximum strain under the pressure load of $0.1 \mathrm{MPa}$ is different from that under the pressure load of $50 \mathrm{MPa}$ and $100 \mathrm{MPa}$. When the pressure loads are respectively $0.1 \mathrm{MPa}, 50 \mathrm{MPa}$, and $100 \mathrm{MPa}$, the location of maximum stress and displacement of the orifice flowmeter are the same.
\end{abstract}

Keywords: Orifice Flowmeter, Finite Element, Load, Maximum Stress

\section{Introduction}

Orifice flowmeter has the advantages of simple structure, reliable operation and low cost, and is widely used to measure natural gas in the petrochemical and urban gas industry $[1,2]$. And the orifice flowmeter is a high-range ratio differential pressure flow device composed of a standard orifice plate and a multi-parameter differential pressure transmitter (or differential pressure transmission, temperature transmitter and pressure transmitter), which can measure the flow of gas, steam, liquid and natural gas [3, 4]. However, the measuring accuracy of the orifice flowmeter is a medium level in the flow sensor, and it is related to many complex factors $[5,6]$, for instance, when measuring natural gas, the accumulation of liquid water in natural gas pipelines or the pressurization of compressors in the process will cause pulsating flow of natural gas fluids [7], and the bend radius of pressure and differential pressure transmitter is too small [8] or the pipe slope is not enough, which will cause the distortion of pressure and differential pressure fluctuation, thus causing inaccurate measurement values $[9,10]$. All in all, the pressure load on the inner wall of the orifice flowmeter has a greater impact on its measuring accuracy [11], from entering the orifice plate to 
flowing through the orifice plate, the pressure drops sharply with the increase of the flow velocity [12], and the pressure drops the fastest at the fastest in the instant passing through the orifice plate [13]. Based on this, the $3 \mathrm{D}$ modeling of the orifice flowmeter is modeled by Solidworks [14], and the finite element analysis of 3D modeling is carried out by simulation software, the distribution and variation of stress, displacement and strain of the orifice flowmeter under the natural conditions are analyzed, which provide a theoretical basis for further improving the orifice flowmeter.

\section{Calculation Method}

The orifice flowmeter is made of 304 stainless steel material, and the attribute of 304 stainless steel materials is shown in Table 1.

Table 1. Attribute of 304 stainless steel materials.

\begin{tabular}{llll}
\hline Elastic modulus & $190000 \mathrm{~N} / \mathrm{mm}^{2}$ & Poisson ratio & 0.29 \\
Medium shear modulus & $75000 \mathrm{~N} / \mathrm{mm}^{2}$ & Mass density & $8000 \mathrm{~kg} / \mathrm{m}^{3}$ \\
Tensile strength & $517.017 \mathrm{~N} / \mathrm{mm}^{2}$ & Yield strength & $206.807 \mathrm{~N} / \mathrm{mm}^{2}$ \\
coefficient of thermal expansion & $1.80 \mathrm{E}-005$ & Coefficient of thermal conductivity & $16 \mathrm{~W} /(\mathrm{m} \cdot \mathrm{K})$ \\
Specific heat capacity & $500 \mathrm{~J} /(\mathrm{kg} \cdot \mathrm{K})$ & & \\
\hline
\end{tabular}

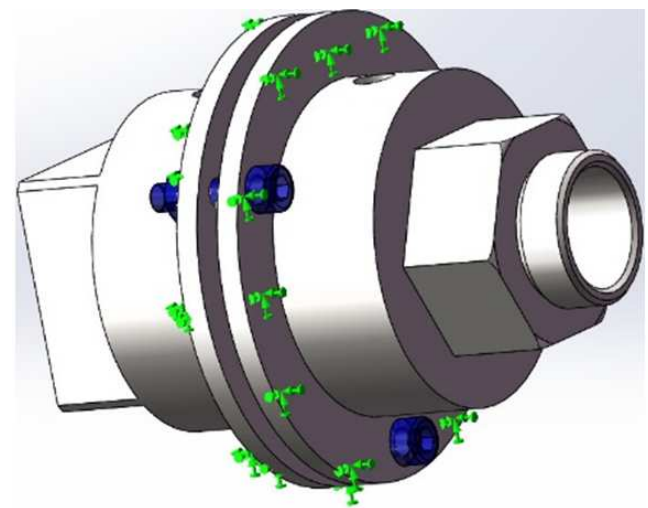

Figure 1. Diagram of fixed middle plate surface of the orifice flowmeter.

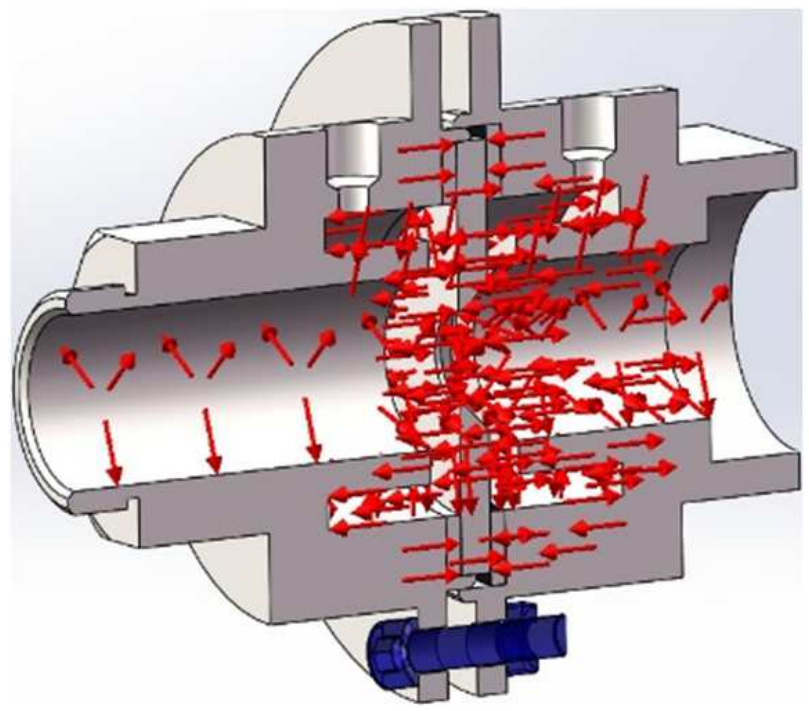

a) Diagram of pressure load
Fix the two plates in the middle of the orifice flowmeter with the definition fixture to achieve no movement of the orifice flowmeter in all directions, as shown in figure 1.

The force surface of the 3D model is loaded to simulate the condition in reality.

In this study, it is necessary to apply pressure load and temperature load on the inner wall of the orifice flowmeter with specific material, and change the additional pressure load on the inner wall of the orifice flowmeter under the premise of constant temperature load, and compare the changes of stress, displacement and strain of the orifice flowmeter. Simulate the pressure load and temperature load of the orifice flowmeter and apply the pressure load and temperature load to the inner wall of the orifice flowmeter, as shown in figure 2.

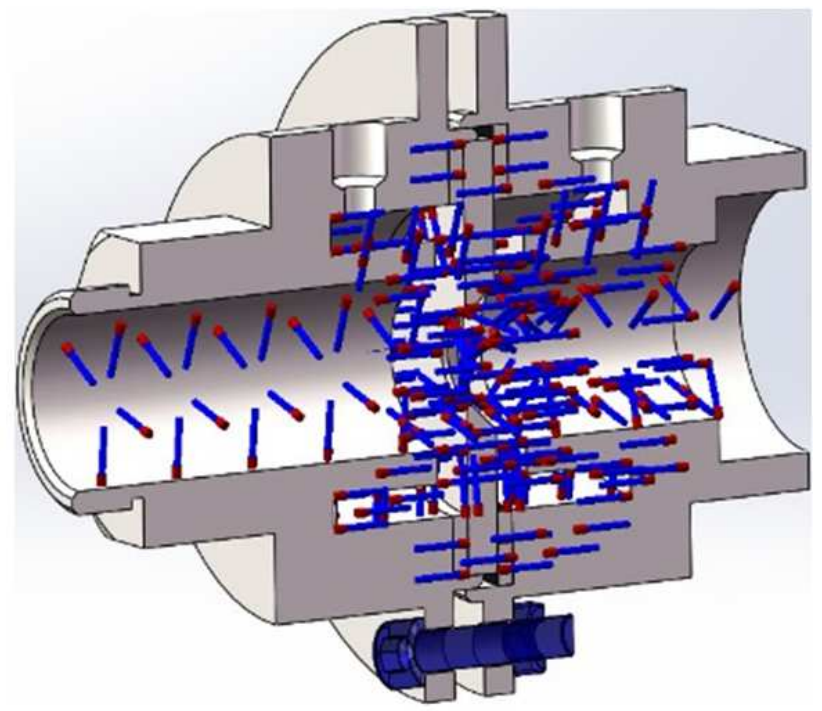

b) Diagram of pressure load

Figure 2. Diagram of load of inner wall of the orifice flowmeter pipeline.

The results are not accurate enough if the grid number is too large, and too small grid number will affect the analysis of structure. Therefore, appropriate grid number should be selected in the analysis process to make the analysis results of some small parts of the orifice flowmeter accurate. Based on this, different grid numbers of the orifice flowmeter are analyzed at $20^{\circ} \mathrm{C}$ and $0.1 \mathrm{MPa}$, as shown in figure 3 , the relation between grid number and average stress, as shown in figure 4 . The appropriate grid number is obtained under the condition of ensuring the accuracy of the results, as shown in figure 5. Through the analysis of example on the three-dimensional model of the orifice flowmeter, the data are obtained and analyzed. 


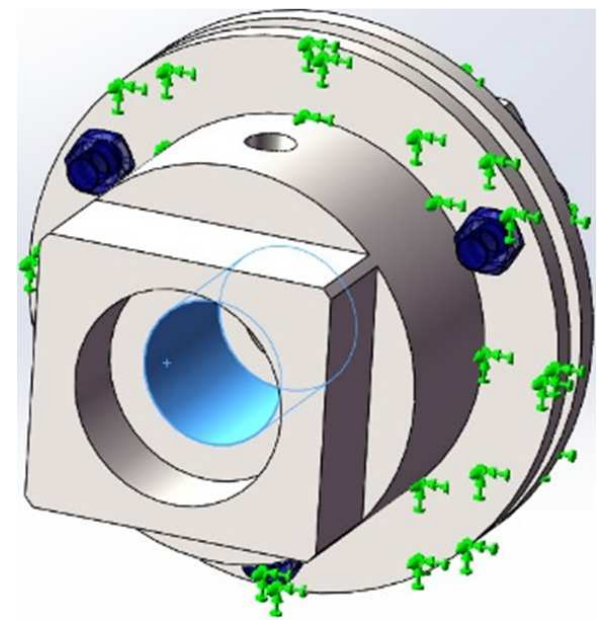

Figure 3. Pressure Surface.

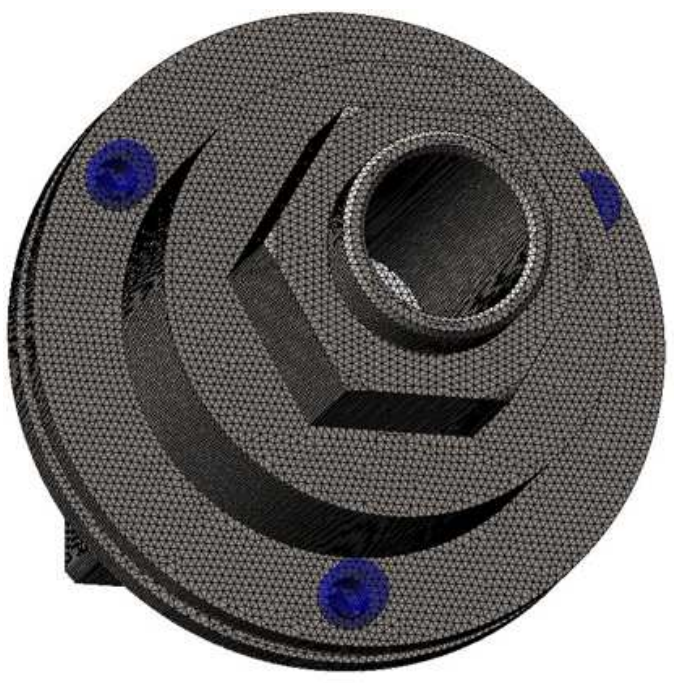

a) Back view

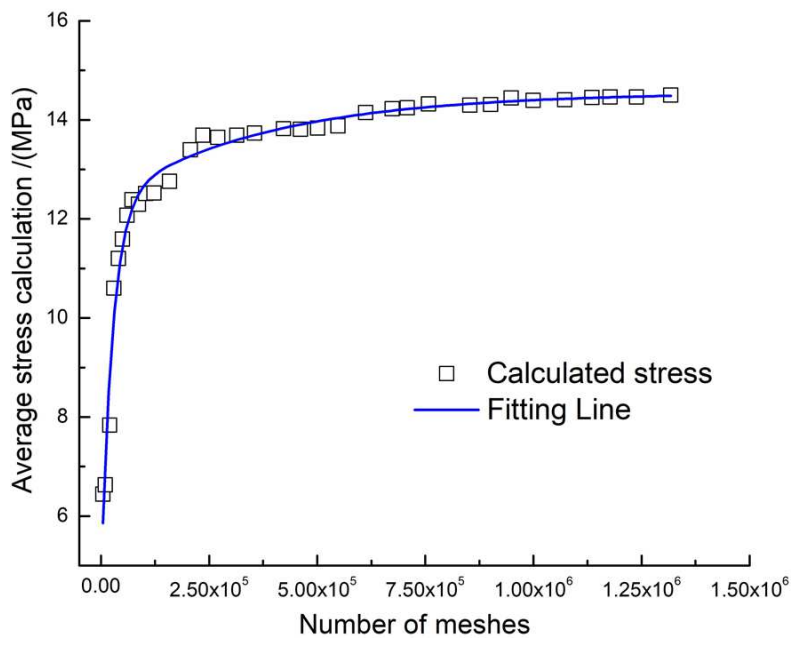

Figure 4. Relation between grid number and stress.

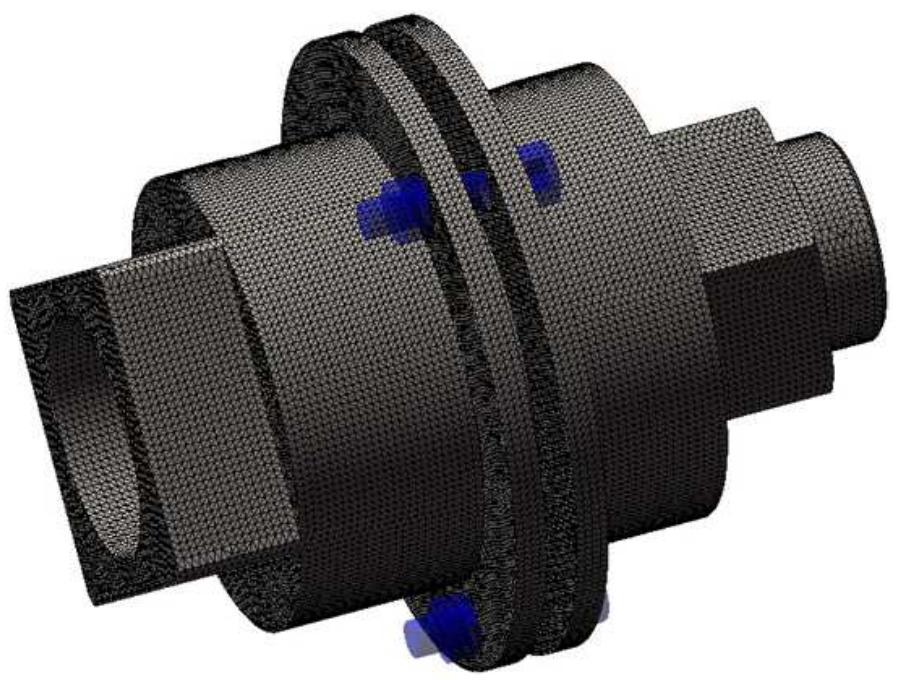

b) Right view

Figure 5. Grid division of the orifice flowmeter.

\section{Result and Discussion}

\subsection{Stress Analysis}

First, a temperature load of $20^{\circ} \mathrm{C}$ and a pressure load of 0.1 $\mathrm{MPa}$ is applied to the inner wall of the orifice flowmeter pipeline, and the results are shown in figure 6.

Figure $6(\mathrm{a})$ is the main view of stress of the orifice flowmeter at $20^{\circ} \mathrm{C}, 0.1 \mathrm{MPa}$ and its detailed data; figure $6(\mathrm{~b})$ is the top view of stress of the orifice flowmeter at $20^{\circ} \mathrm{C}, 0.1$ $\mathrm{MPa}$ and its detailed data; figure 6(c) is the left view of stress of the orifice flowmeter at $20^{\circ} \mathrm{C}, 0.1 \mathrm{MPa}$ and its detailed data; figure $6(\mathrm{~d})$ is the cutaway view of stress of the orifice flowmeter at $20^{\circ} \mathrm{C}, 0.1 \mathrm{MPa}$ and its details data.

Figure 6(a) and figure 6(b) show that the stress on the orifice flowmeter is concentrated in the middle groove of the inner wall of the pipeline. The stress of the orifice flowmeter reaches the maximum value in the middle groove of the inner wall of the pipeline, the value is $24.53526 \mathrm{MPa}$, the minimum value is obtained at the outlet, the value is $0.0001106186 \mathrm{MPa}$. Figure 6(a) shows that the maximum stress at the outlet of the orifice flowmeter is $2.044707 \mathrm{MPa}$, the minimum stress at the outlet of the orifice flowmeter is $0.0001106186 \mathrm{MPa}$; figure 6(b) and figure 6(c) show the maximum stress at the inlet of the orifice flowmeter is $6.133899 \mathrm{MPa}$, the minimum stress at the inlet of the orifice flowmeter is $2.044707 \mathrm{MPa}$; figure $6(\mathrm{~d})$ shows that the maximum stress of the orifice flowmeter in the inner wall of the pipeline is $24.53526 \mathrm{MPa}$, and the minimum stress of the orifice flowmeter in the inner wall of the pipeline is $10.22309 \mathrm{MPa}$.

The temperature load applied to the inner wall of the orifice flowmeter pipeline is kept constant, and the pressure load is increased from $0.1 \mathrm{MPa}$ to $50 \mathrm{MPa}$., the results are shown in figure 7. 


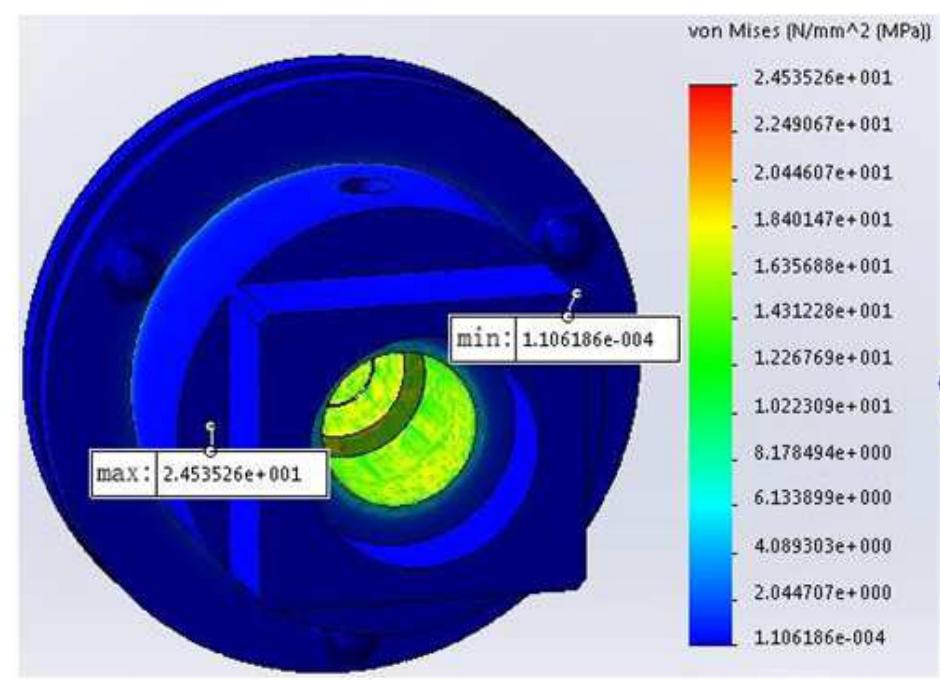

a) Main view

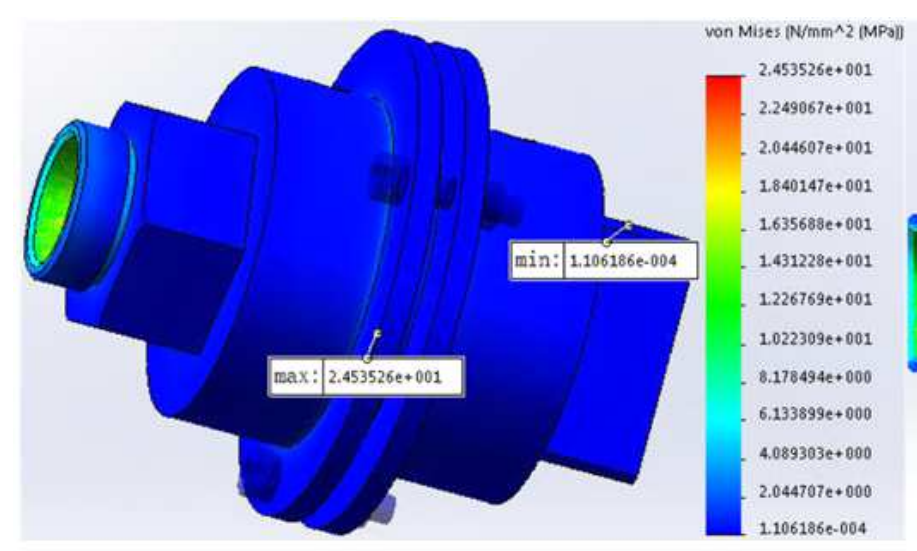

c) Left view

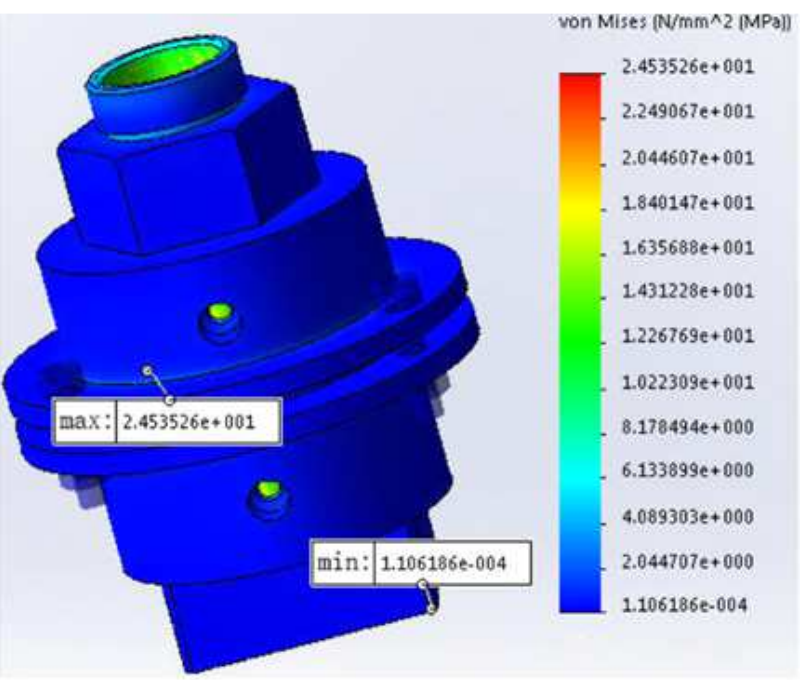

b) Top View

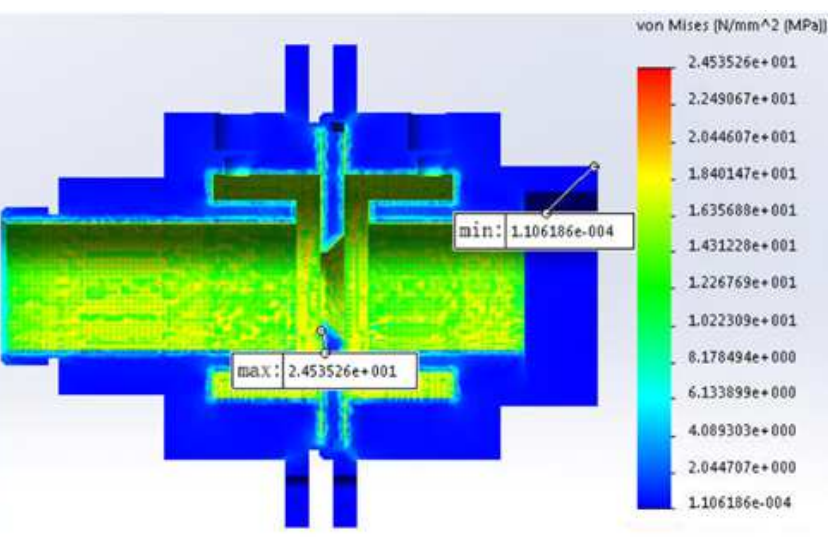

d) Cutaway view

Figure 6. Stress diagram $\left(20^{\circ} \mathrm{C}, 0.1 \mathrm{MPa}\right)$.

Figure $7(\mathrm{a})$ is the main view of stress of the orifice flowmeter at $20^{\circ} \mathrm{C}, 50 \mathrm{MPa}$ and its detailed data; figure $7(\mathrm{~b})$ is the top view of stress of the orifice flowmeter at $20^{\circ} \mathrm{C}, 50 \mathrm{MPa}$ and its detailed data; figure 7(c) is the left view of stress of the orifice flowmeter at $20^{\circ} \mathrm{C}, 50 \mathrm{MPa}$ and its detailed data; figure $7(d)$ is the cutaway view of stress of the orifice flowmeter at $20^{\circ} \mathrm{C}, 50 \mathrm{MPa}$ and its detailed data.

Comparing the changes, the location of stress concentration changes from the middle groove of the inner wall of the pipeline of the orifice flowmeter to the inlet. Figure 7(a) and figure 7(b) show that the stress of the orifice flowmeter reaches a maximum at the inlet, the value is $239.3233 \mathrm{MPa}$, which is $214.78804 \mathrm{MPa}$ larger than that of the orifice flowmeter pipeline when $20^{\circ} \mathrm{C}$ and $0.1 \mathrm{MPa}$ are applied to the inner wall. A minimum value is obtained at the outlet, the value is $0.09876456 \mathrm{MPa}$, which is $0.0986539414 \mathrm{MPa}$ larger than that of the orifice flowmeter pipeline when $20^{\circ} \mathrm{C}$ and $0.1 \mathrm{MPa}$ are applied to the inner wall. Figure 7(a) shows that the maximum stress at the outlet of the orifice flowmeter is $59.90489 \mathrm{MPa}$, the minimum is $0.09876456 \mathrm{MPa}$ at its outlet; figure $7(\mathrm{c})$ shows that the maximum stress at the inlet of the orifice flowmeter is $239.3233 \mathrm{MPa}$, the minimum is $99.77563 \mathrm{MPa}$ at its inlet; figure 7(d) shows that the maximum stress at the inner wall of the orifice flowmeter pipeline is 179.5171 $\mathrm{MPa}$, and the minimum is $20.03414 \mathrm{MPa}$ at its inner wall. It can be seen that the location of the minimum stress of the orifice flowmeter is basically unchanged when the temperature load is unchanged and the pressure load is increased from $0.1 \mathrm{MPa}$ to $50 \mathrm{MPa}$, the value is increased by $0.0986539414 \mathrm{MPa}$, and the location of maximum of stress changes from the middle groove of the inner wall of the orifice flowmeter pipeline to the inlet, and the change is large, increased by $214.78804 \mathrm{MPa}$. 


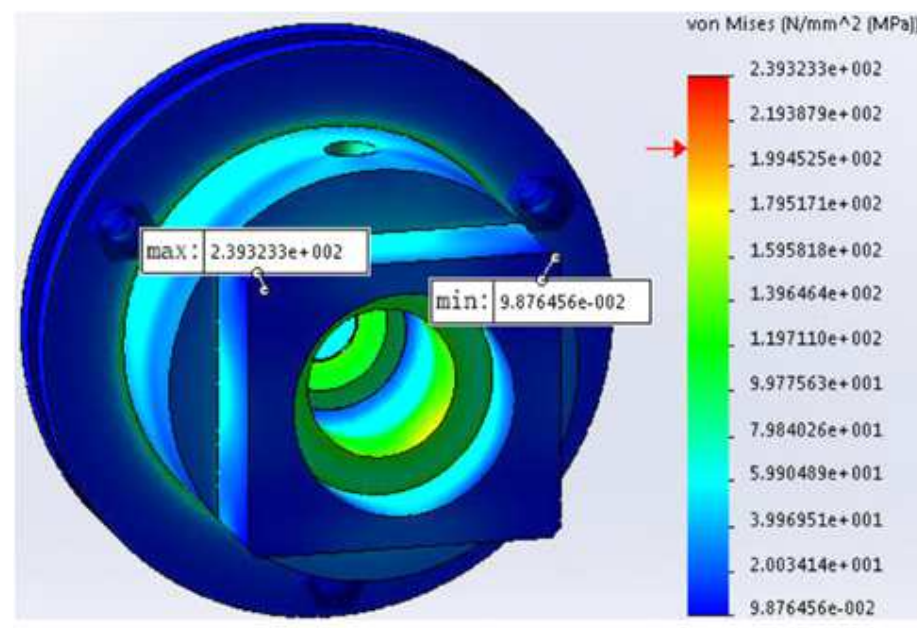

a) Main view

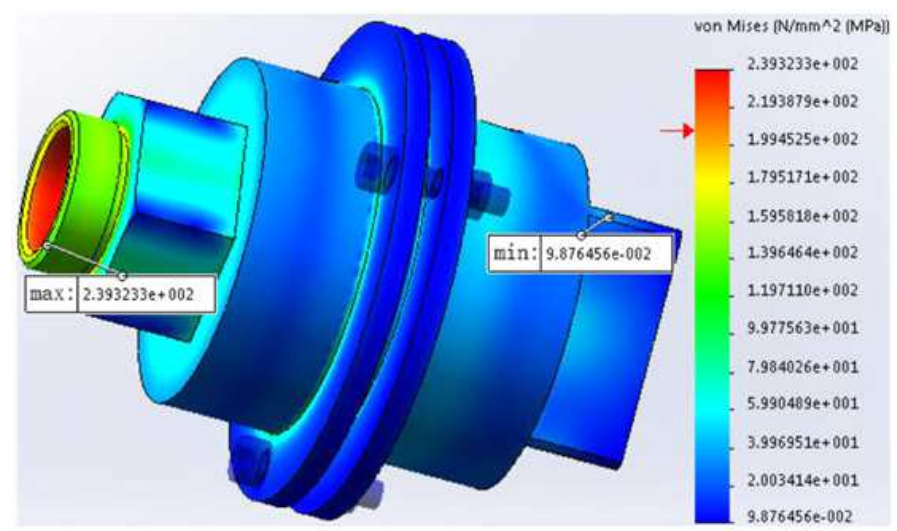

c) Left view

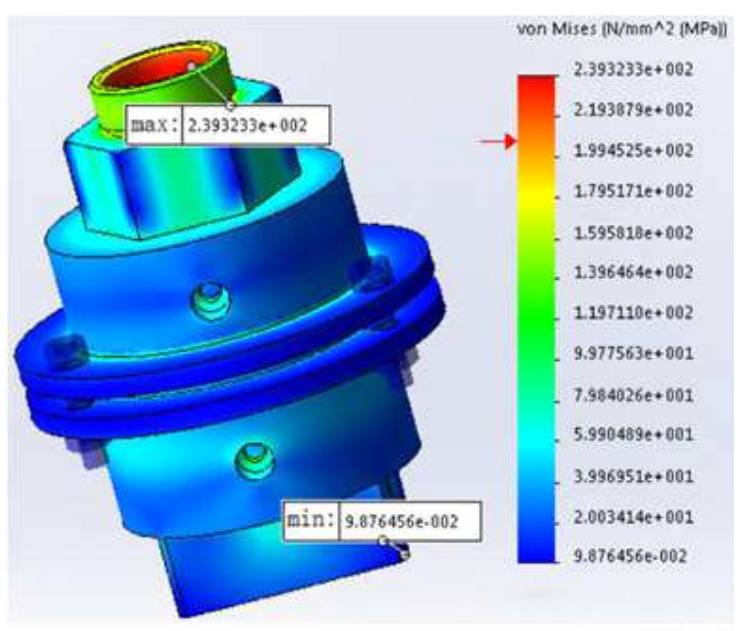

b) Top view

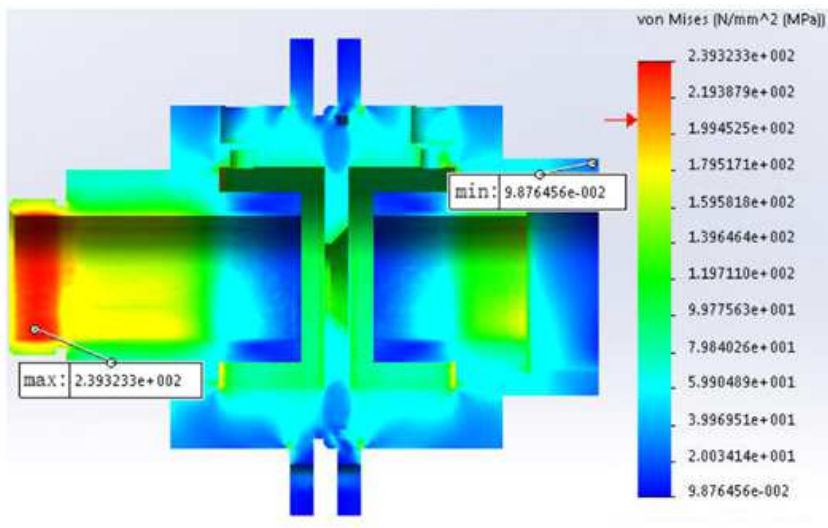

d) Cutaway view

Figure 7. Stress diagram $\left(20^{\circ} \mathrm{C}, 50 \mathrm{MPa}\right)$.

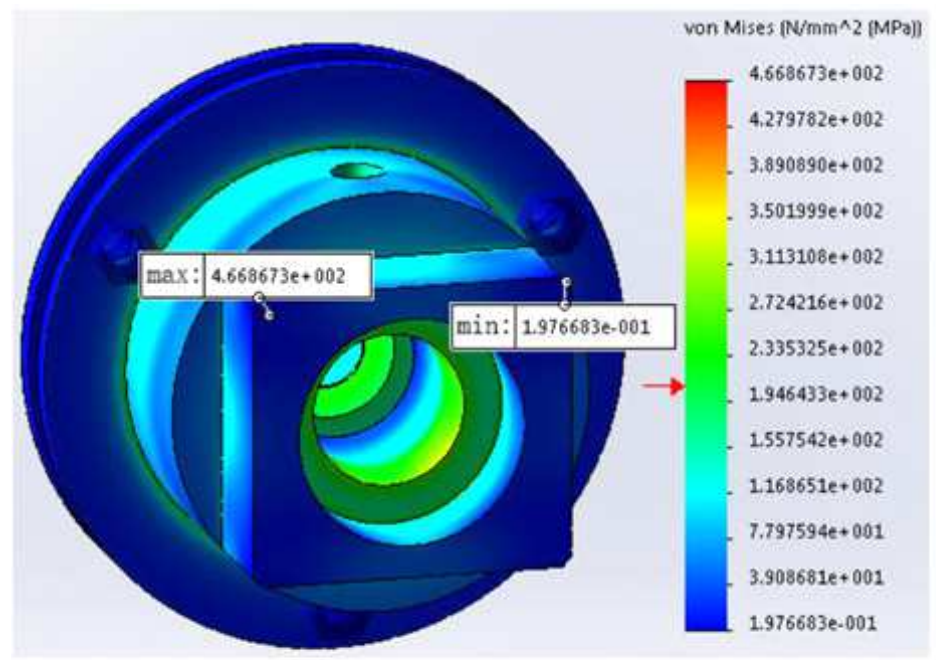

a) Main view

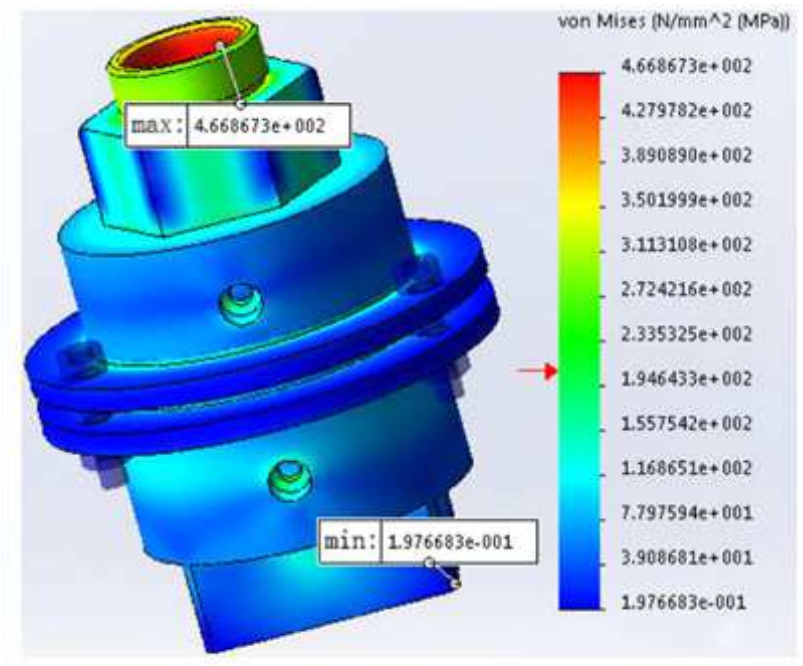

b) Top view 


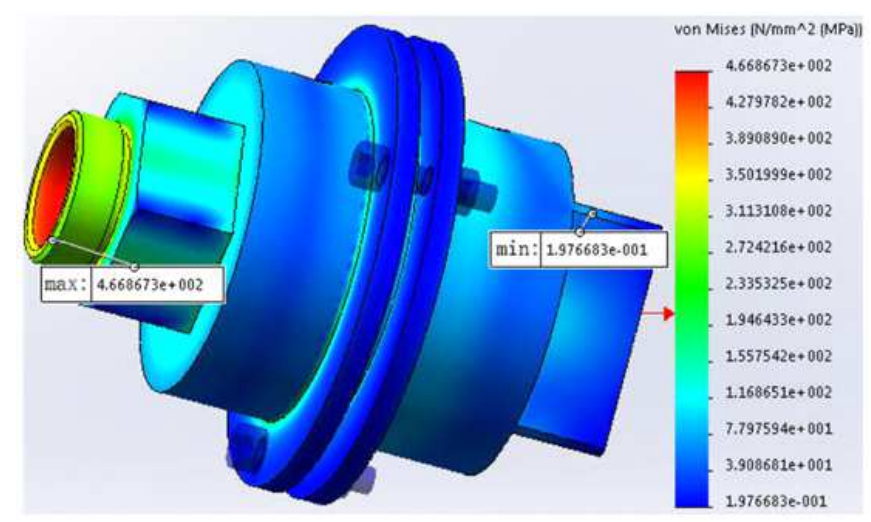

c) Left view

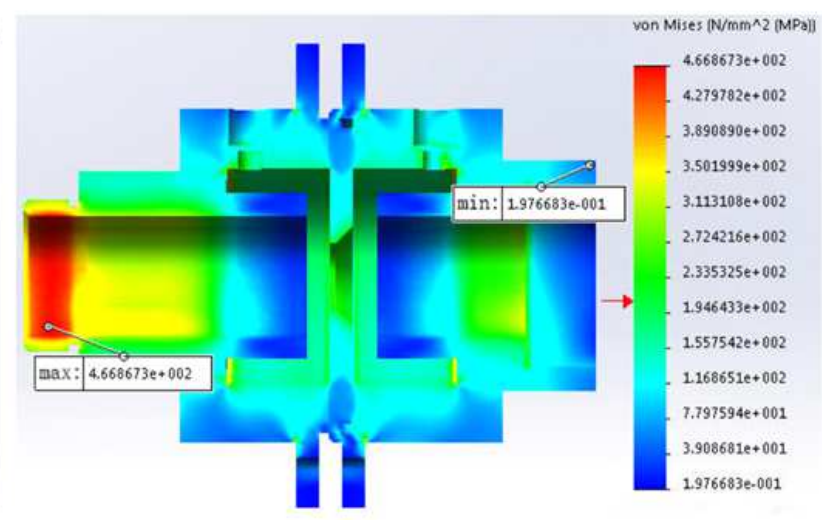

d) Cutaway view

Figure 8. Stress diagram $\left(20^{\circ} \mathrm{C}, 100 \mathrm{MPa}\right)$.

The temperature load applied to the inner wall of the orifice flowmeter pipeline is kept constant, and the pressure load is increased from $50 \mathrm{MPa}$ to $100 \mathrm{MPa}$. The results are shown in figure 8.

Figure $8(\mathrm{a})$ is the main view of stress of the orifice flowmeter at $20^{\circ} \mathrm{C}, 100 \mathrm{MPa}$ and its detailed data; figure $8(\mathrm{~b})$ is the top view of stress of the orifice flowmeter at $20^{\circ} \mathrm{C}, 100$ $\mathrm{MPa}$ and its detailed data; figure $8(\mathrm{c})$ is the left view of stress of the orifice flowmeter at $20^{\circ} \mathrm{C}, 100 \mathrm{MPa}$ and its detailed data; figure $8(\mathrm{~d})$ is the cutaway view of stress of the orifice flowmeter at $20^{\circ} \mathrm{C}, 100 \mathrm{MPa}$ and its detailed data.

Comparing the changes, the location of stress is still concentrated at the inlet of the orifice flowmeter. figure 8(a) and figure $8(\mathrm{~b})$ show that the stress of the orifice flowmeter reaches a maximum at its inlet, the value is $466.8673 \mathrm{MPa}$, which is $227.544 \mathrm{MPa}$ larger than that of the orifice flowmeter when $20^{\circ} \mathrm{C}$ and $50 \mathrm{MPa}$ are applied to the inner wall. A minimum stress is obtained at the outlet of the orifice flowmeter, the value is $0.1976683 \mathrm{MPa}$, which is 0.09890374 $\mathrm{MPa}$ higher than that applied to the orifice flowmeter at $20^{\circ} \mathrm{C}$ and $50 \mathrm{MPa}$. figure 8(a) shows that the maximum stress at the outlet of the orifice flowmeter is $116.8651 \mathrm{MPa}$ and its minimum stress is $0.1976683 \mathrm{MPa}$; figure $8(\mathrm{c})$ shows that the maximum stress at the inlet of the orifice flowmeter is $466.8673 \mathrm{MPa}$, the minimum stress at its inlet is 194.6433 $\mathrm{MPa}$. It can be seen that the location of the minimum stress of the orifice flowmeter is basically unchanged when the temperature load is unchanged and the pressure load is increased from $50 \mathrm{MPa}$ to $100 \mathrm{MPa}$, and the value is increased by $0.09890374 \mathrm{MPa}$, and the location of maximum stress is still at the inlet of the orifice flowmeter, but the change is large, increased by $227.544 \mathrm{MPa}$.

From the comparison of the above data, we can see that: when the temperature load is $20^{\circ} \mathrm{C}$ and remains unchanged, the stress change of the orifice flowmeter is positively correlated with the change of the additional pressure load, and the maximum stress is also increased, as shown in figure 9. Under the condition of temperature load of $20^{\circ} \mathrm{C}$ and pressure load of $0.1 \mathrm{MPa}$, the maximum stress of the orifice flowmeter occurs in the thinnest part of the orifice plate, when the temperature load remains unchanged and the pressure load is
$50 \mathrm{MPa}$ and $100 \mathrm{MPa}$, the maximum stress of the orifice flowmeter occurs at its inlet.

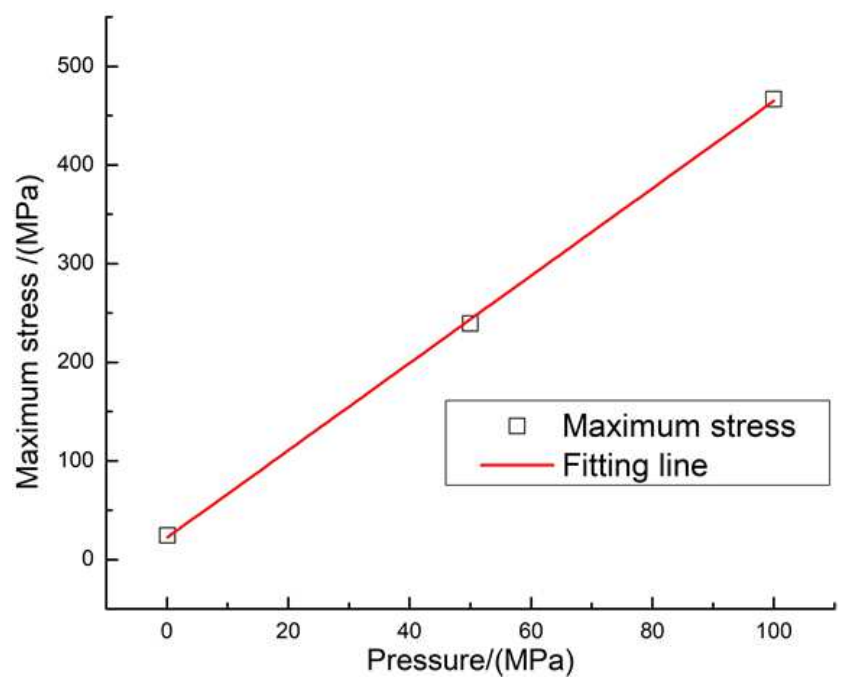

Figure 9. Diagram of relation between maximum stress and pressure at $20^{\circ} \mathrm{C}$.

\subsection{Displacement Analysis}

First, a temperature load of $20^{\circ} \mathrm{C}$ and a pressure load of 0.1 $\mathrm{MPa}$ is applied to the inner wall of the orifice flowmeter pipeline, and the results are shown in figure 10.

Figure 10(a) is the main view of displacement of the orifice flowmeter at $20^{\circ} \mathrm{C}, 0.1 \mathrm{MPa}$ and its detailed data; figure $10(\mathrm{~b})$ is the top view of displacement of the orifice flowmeter at $20^{\circ} \mathrm{C}, 0.1 \mathrm{MPa}$ and its detailed data; figure $10(\mathrm{c})$ is the left view of displacement of the orifice flowmeter at $20^{\circ} \mathrm{C}, 0.1$ $\mathrm{MPa}$ and its detailed data; figure $10(\mathrm{~d})$ is the cutaway view of displacement of the orifice flowmeter at $20^{\circ} \mathrm{C}, 0.1 \mathrm{MPa}$ and its details data.

Figure 10(a) and figure 10(d) show that the orifice flowmeter has the largest displacement change at the middle wall surface of the inner wall of the pipeline, and the value is $0.0002845755 \mathrm{~mm}$, and the displacement change at the two fixed plate faces is the smallest, almost close to $0 \mathrm{~mm}$. Figure 10 (a) shows that the maximum displacement at the outlet of the orifice flowmeter is $0.00007114387 \mathrm{~mm}$, the minimum is $0.00004742928 \mathrm{~mm}$; figure 10 (b) shows that the maximum 
displacement at the inlet of the orifice flowmeter is $0.0002371462 \mathrm{~mm}$, the minimum is $0.00009485849 \mathrm{~mm}$; figure $10(\mathrm{~d})$ shows that the maximum displacement of the inner wall of the orifice flowmeter pipeline is 0.0002845755 $\mathrm{mm}$, and its minimum displacement is $0.00002371462 \mathrm{~mm}$.

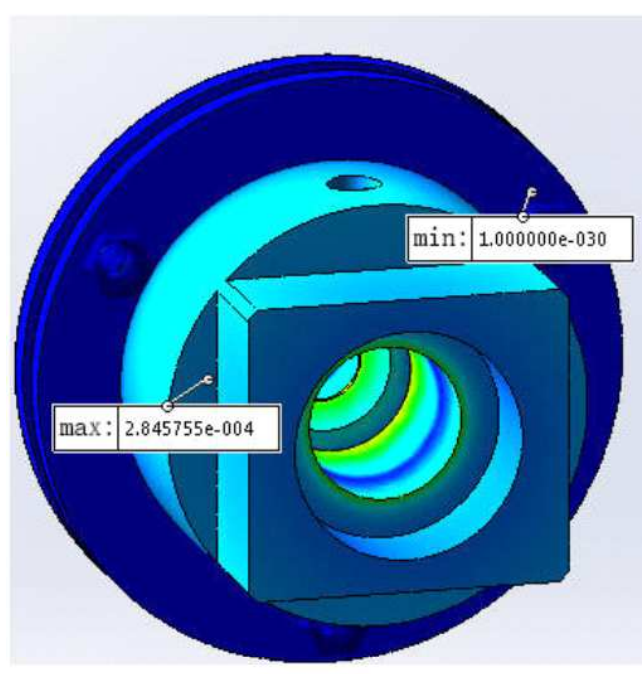

a) Main view

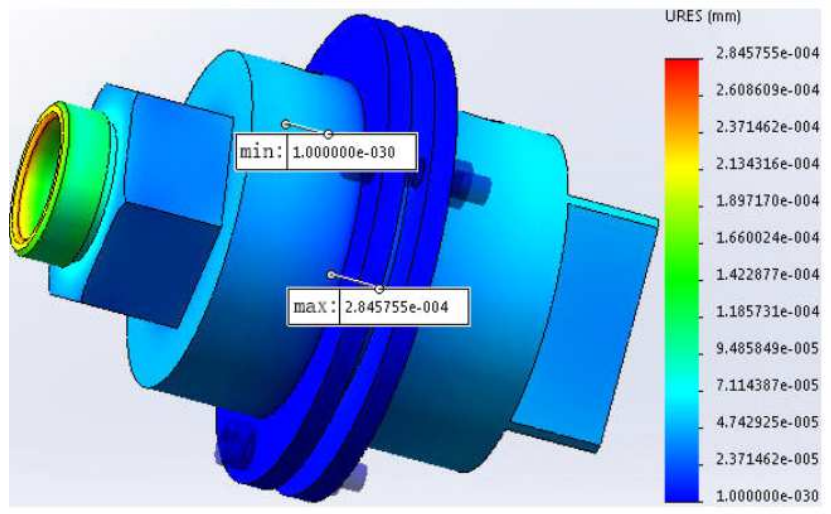

c) Left view

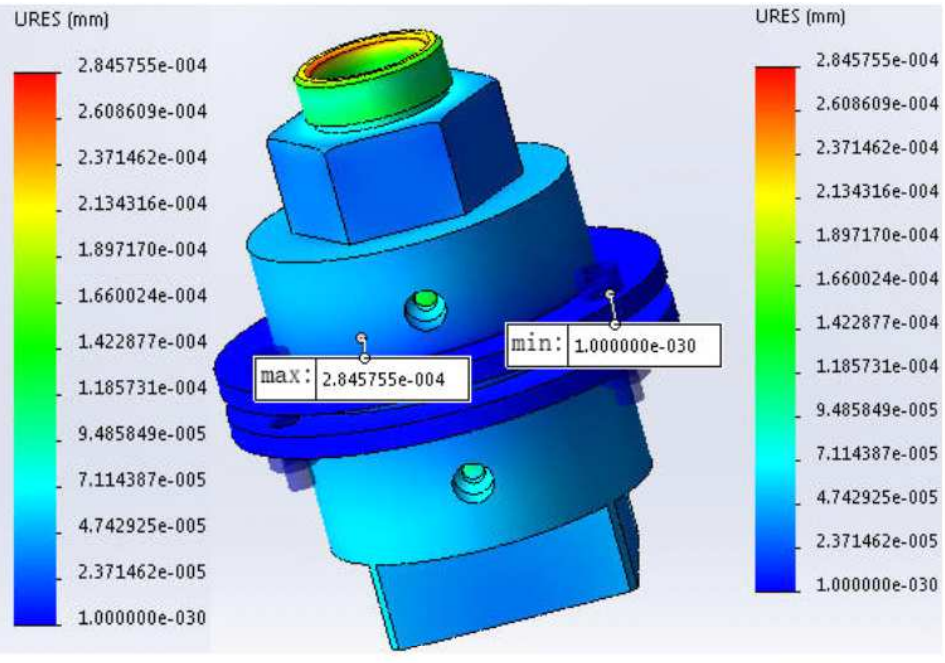

b) Top view

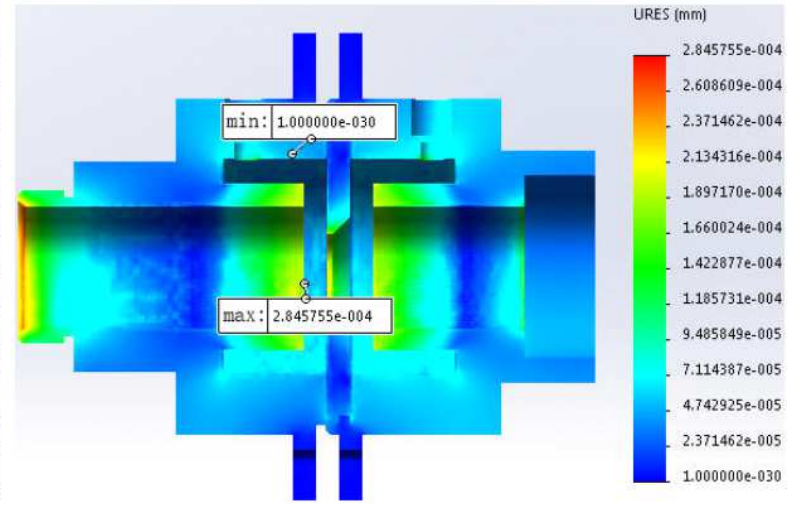

d) Cutaway view

Figure 10. Displacement diagram $\left(20^{\circ} \mathrm{C}, 0.1 \mathrm{MPa}\right)$.

The temperature load on the inner wall of the orifice flowmeter pipeline is kept constant, and the pressure load is increased from $0.1 \mathrm{MPa}$ to $50 \mathrm{MPa}$, the results are shown in figure 11 .

Figure 11(a) is the main view of displacement of the orifice flowmeter at $20^{\circ} \mathrm{C}, 50 \mathrm{MPa}$ and its detailed data; figure $11(\mathrm{~b})$ is the top view of displacement of the orifice flowmeter at $20^{\circ} \mathrm{C}, 50 \mathrm{MPa}$ and its detailed data; figure $11(\mathrm{c})$ is the left view of displacement of the orifice flowmeter at $20^{\circ} \mathrm{C}, 50$ $\mathrm{MPa}$ and its detailed data; figure $11(\mathrm{~d})$ is the cutaway view of displacement of the orifice flowmeter at $20^{\circ} \mathrm{C}, 50 \mathrm{MPa}$ and its detailed data.

Figure 11 (a) and figure 11 (d) show that the location of displacement of the orifice flowmeter is changed from the middle wall of the inner wall of the pipe to the inlet of the pipeline, and the value is $0.01523324 \mathrm{~mm}$, which is increased by $0.0149486645 \mathrm{~mm}$ when $20^{\circ} \mathrm{C}$ and $0.1 \mathrm{MPa}$ are applied to the inner wall of the orifice flowmeter pipeline, the minimum displacement is still on the two fixed plates, almost close to zero. Figure 11 (a) shows the maximum displacement at the outlet of the orifice flowmeter is $0.005077747 \mathrm{~mm}$, the minimum is $0.002538874 \mathrm{~mm}$; figure 11 (b) and figure 11 (c) show the maximum displacement at the inlet of the orifice flowmeter is $0.1523324 \mathrm{~mm}$, the minimum is $0.01142493 \mathrm{~mm}$; figure 11 (d) shows that the maximum displacement at the inner wall of the orifice flowmeter pipe is $0.01396380 \mathrm{~mm}$, and the minimum is $0.003808310 \mathrm{~mm}$. It can be seen that the orifice flowmeter has a temperature load of $20^{\circ} \mathrm{C}$ and remains unchanged, when the pressure load is increased from $0.1 \mathrm{MPa}$ to $50 \mathrm{MPa}$, the location of the maximum displacement is changed from the middle wall of the inner wall of the pipeline to the inlet, and the value is increased by $0.0149486645 \mathrm{~mm}$, the location of the minimum displacement remains unchanged, and the value is still almost to zero.

The temperature load applied to the inner wall of the orifice flowmeter pipeline is kept constant, and the pressure load is increased from $50 \mathrm{MPa}$ to $100 \mathrm{MPa}$. The results are shown in figure 12 .

Figure 12(a) is the main view of displacement of the orifice flowmeter at $20^{\circ} \mathrm{C}, 100 \mathrm{MPa}$ and its detailed data; figure 12 (b) is the top view of displacement of the orifice flowmeter at $20^{\circ} \mathrm{C}, 100 \mathrm{MPa}$ and its detailed data; figure $12(\mathrm{c})$ is the left 
view of displacement of the orifice flowmeter at $20^{\circ} \mathrm{C}, 100$ $\mathrm{MPa}$ and its detailed data; figure $12(\mathrm{~d})$ is the cutaway view of displacement of the orifice flowmeter at $20^{\circ} \mathrm{C}, 100 \mathrm{MPa}$ and its detailed data.

Figure 12 (a) and Figure 12 (d) show that the maximum displacement is still at its inlet, the value is $0.03052111 \mathrm{~mm}$, which is increased by $0.0149486645 \mathrm{~mm}$ when $20^{\circ} \mathrm{C}$ and 50 $\mathrm{MPa}$ are applied to the inner wall of the orifice flowmeter pipeline, the minimum displacement is still on the two fixed plates, almost close to zero. Figure 12 (a) shows the maximum displacement at the outlet of the orifice flowmeter is $0.01271713 \mathrm{~mm}$, the minimum is $0.005086851 \mathrm{~mm}$; figure 12 (b) and figure 12 (c) show the maximum displacement at the inlet of the orifice flowmeter is $0.03052111 \mathrm{~mm}$, the minimum is $0.02289083 \mathrm{~mm}$; figure 12 (d) shows that the maximum displacement at the inner wall of the orifice flowmeter pipe is $0.02797768 \mathrm{~mm}$, and the minimum is $0.007630277 \mathrm{~mm}$. It can be seen that the orifice flowmeter has a temperature load of $20^{\circ} \mathrm{C}$ and remains unchanged, when the pressure load is increased from $50 \mathrm{MPa}$ to $100 \mathrm{MPa}$, the location of the maximum displacement is at the inlet, and the value is increased by $0.01528789 \mathrm{~mm}$, the location of the minimum displacement remains unchanged, and the value is still almost to zero.

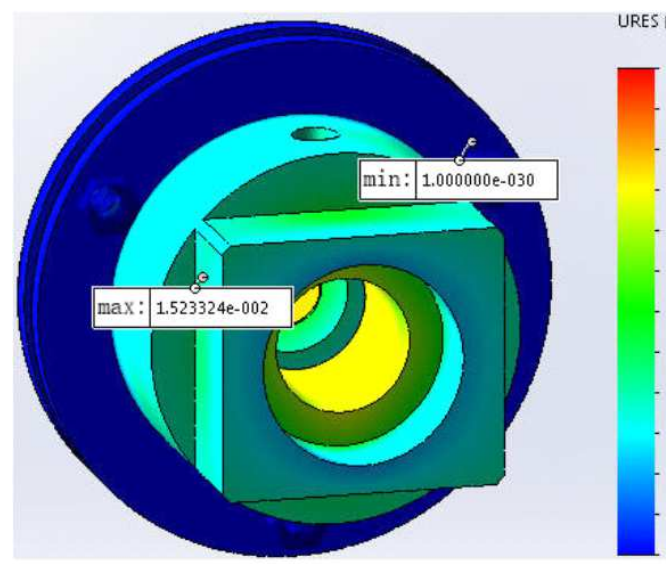

a) Main view

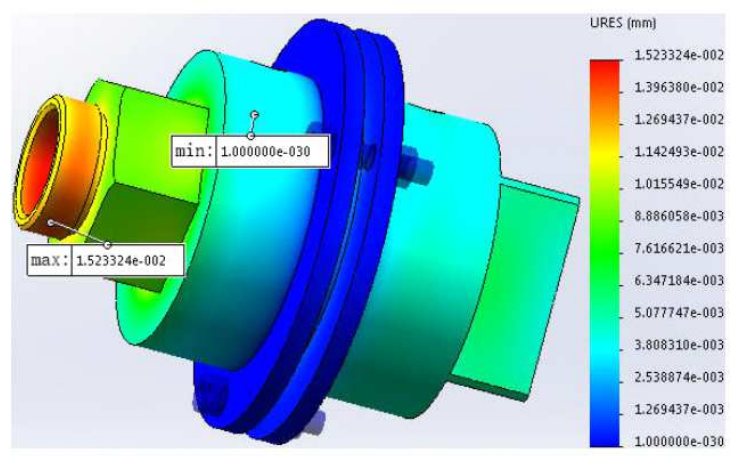

c) Left view

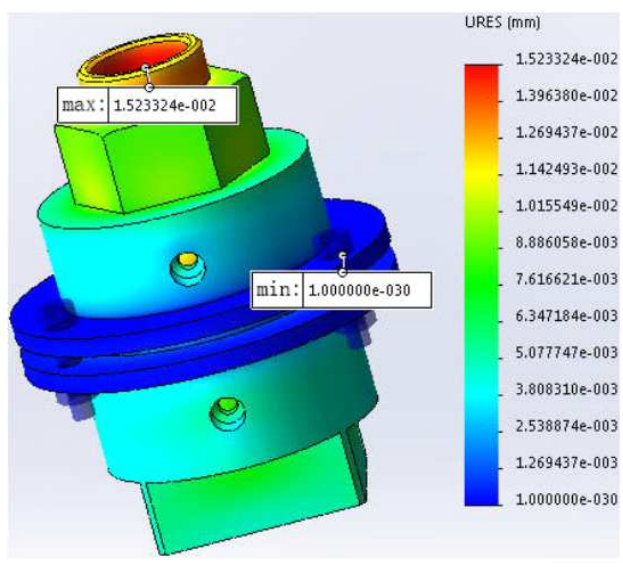

b) Top view

Figure 11. Displacement diagram $\left(20^{\circ} \mathrm{C}, 50 \mathrm{MPa}\right)$.

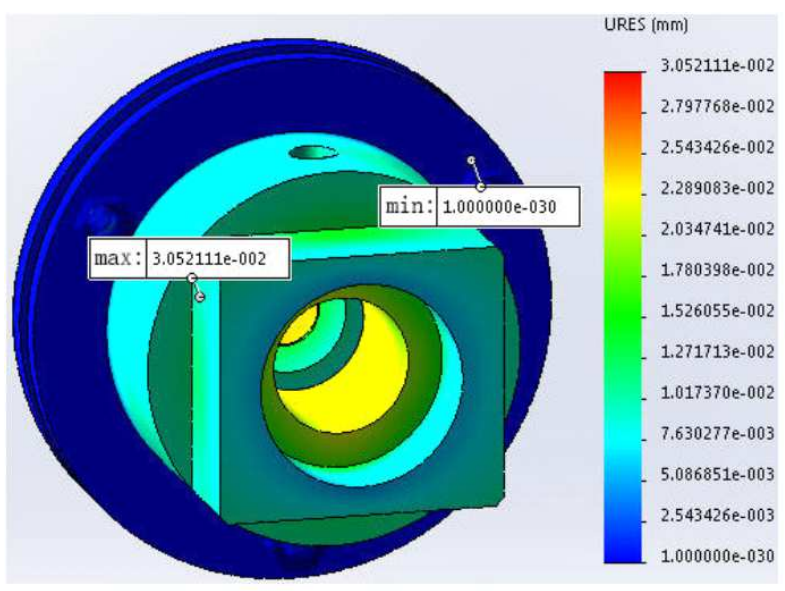

a) Main view

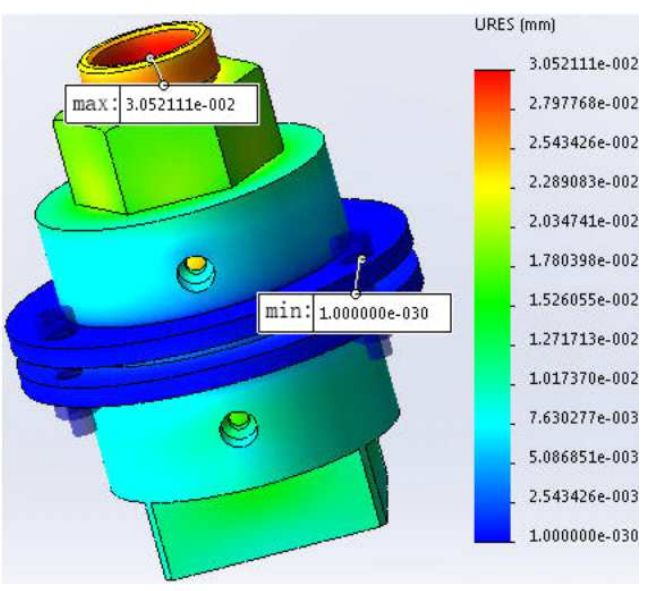

b) Top view d) Cutaway view

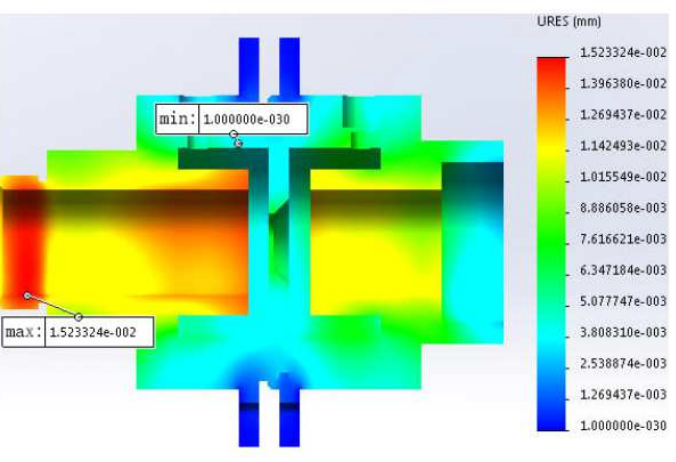




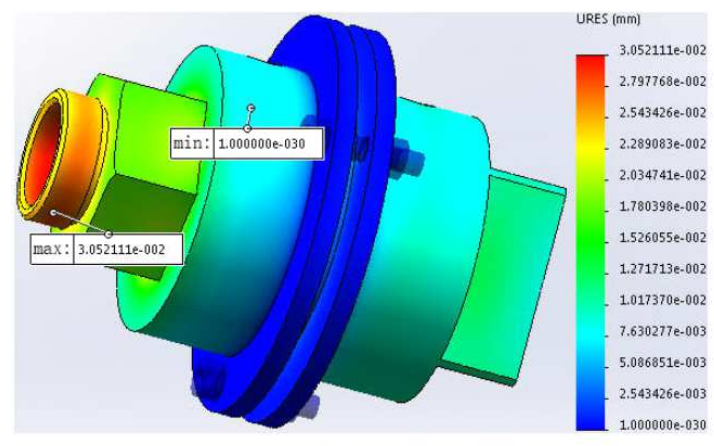

c) Left view

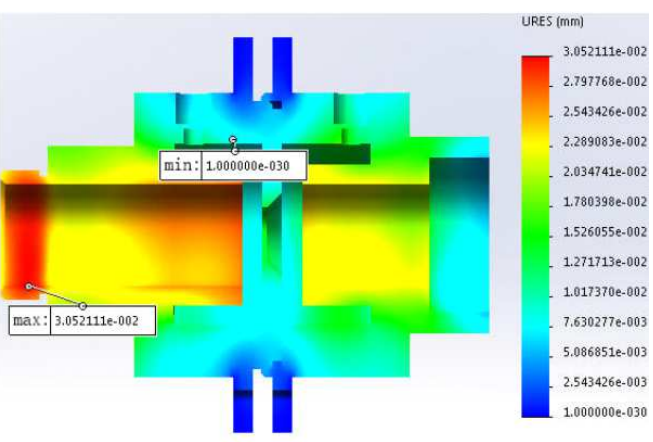

d) Cutaway view

Figure 12. Displacement diagram $\left(20^{\circ} \mathrm{C}, 100 \mathrm{MPa}\right)$.

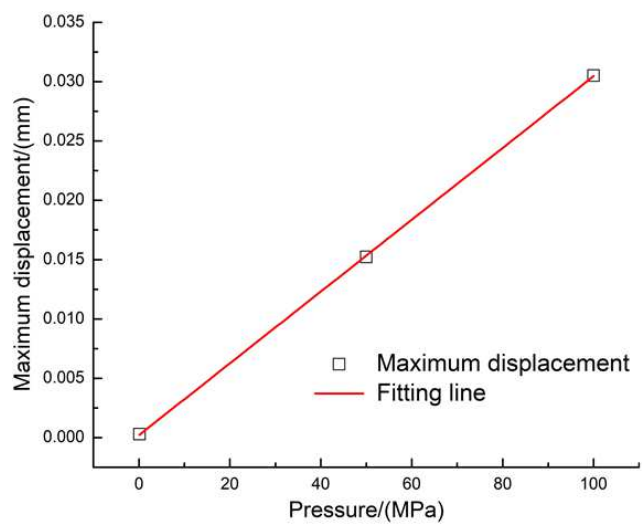

Figure 13. Diagram of relation between maximum displacement and pressure at $20^{\circ} \mathrm{C}$.

From the comparison of the above data, we can see that: when the temperature load is $20^{\circ} \mathrm{C}$ and remains unchanged, the displacement change of the orifice flowmeter is positively correlated with the change of the additional pressure load, and the maximum displacement is also increased, as shown in figure 13. Except that the temperature load is $20^{\circ} \mathrm{C}$ and the pressure load is $0.1 \mathrm{MPa}$, the location of maximum of displacement of the orifice flowmeter appears in the middle groove of the inner wall of the pipeline, in other cases, the location of maximum of displacement appears at the inlet.

\subsection{Strain Analysis}

Like the stress and displacement analysis, first, a temperature load of $20^{\circ} \mathrm{C}$ and a pressure load of $0.1 \mathrm{MPa}$ are applied to the inner wall of the orifice flowmeter pipeline, and the results are shown in figure 14.

Figure $14(\mathrm{a})$ is the main view of strain of the orifice flowmeter at $20^{\circ} \mathrm{C}, 0.1 \mathrm{MPa}$ and its detailed data; figure $14(\mathrm{~b})$ is the top view of strain of the orifice flowmeter at $20^{\circ} \mathrm{C}, 0.1$ $\mathrm{MPa}$ and its detailed data; figure 14(c) is the left view of strain of the orifice flowmeter at $20^{\circ} \mathrm{C}, 0.1 \mathrm{MPa}$ and its detailed data; figure $14(\mathrm{~d})$ is the cutaway view of strain of the orifice flowmeter at $20^{\circ} \mathrm{C}, 0.1 \mathrm{MPa}$ and its details data.

Figures 14 (a) and figure 14 (d) show that the orifice flowmeter has the largest strain in its casing, the value is 0.00072474418 , the strain at the exit of the orifice flowmeter is the smallest, the value is 0.000000001211225 . Figure 14 (a) shows the maximum strain of the orifice flowmeter the orifice flowmeter outlet is 0.000012080004 , the minimum is 0.000000001211225 ; figure 14 (b) and figure 14 (c) show the maximum strain at the inlet of the orifice flowmeter is 0.00003623770 , the minimum is 0.000006040626 ; figure 14 (d) shows that the maximum strain at the inner wall of the orifice flowmeter pipe is 0.00006039536 , and the minimum is 0.00003019828 .

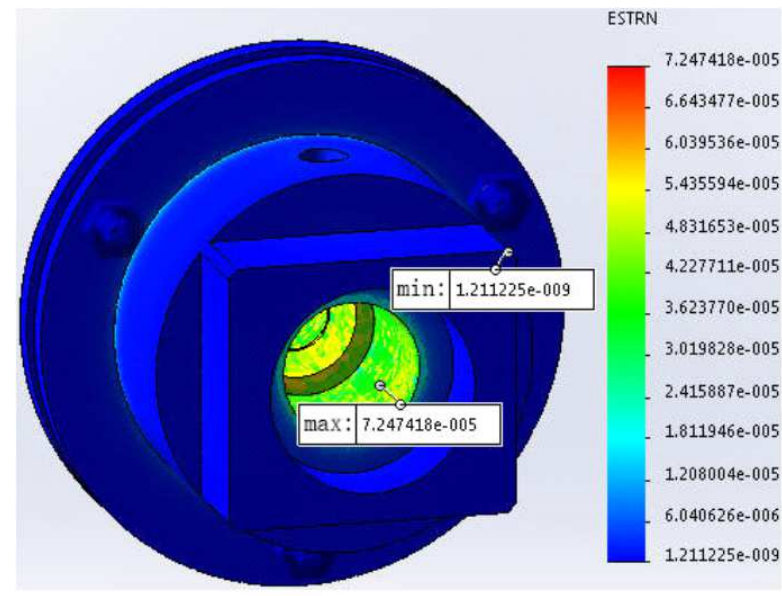

a) Main view

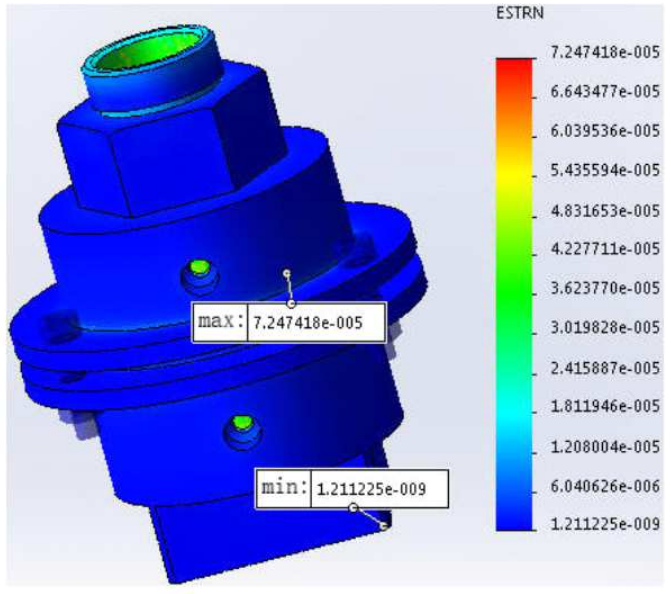

b) Top view 


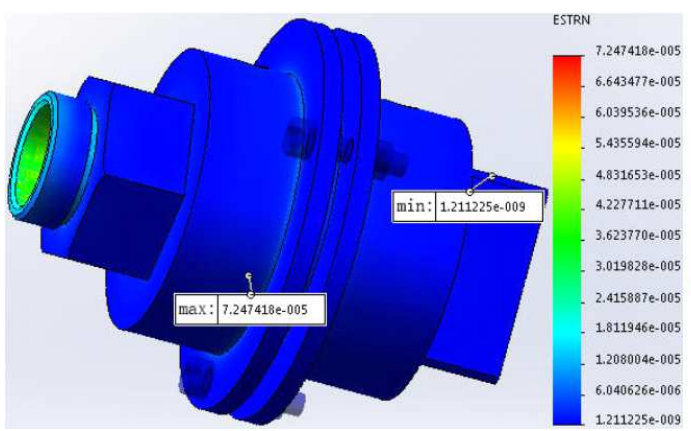

c) Left view

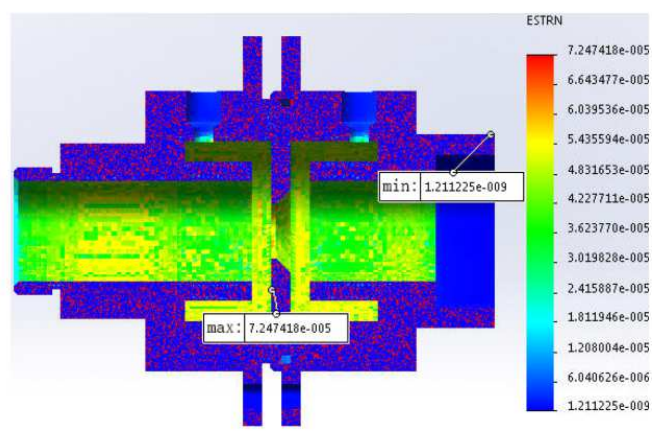

d) Cutaway view

Figure 14. Strain diagram $\left(20^{\circ} \mathrm{C}, 0.1 \mathrm{MPa}\right)$

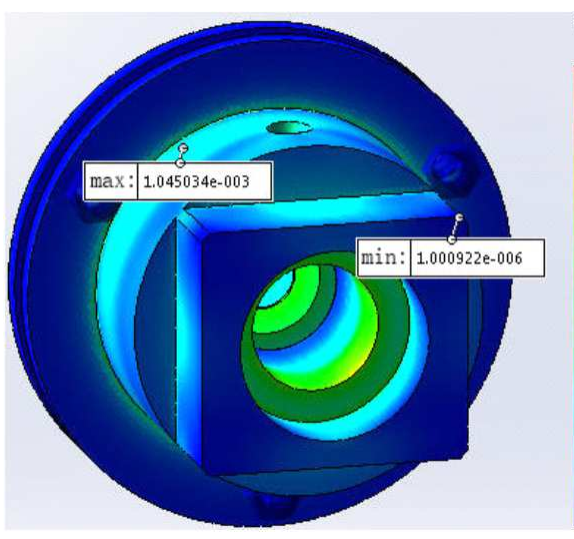

a) Main view

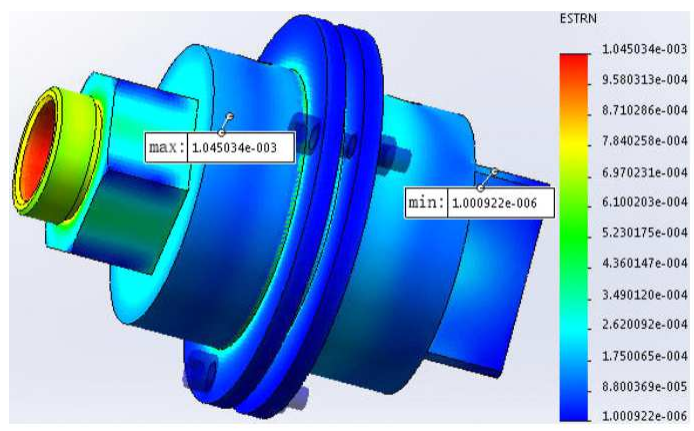

c) Left view
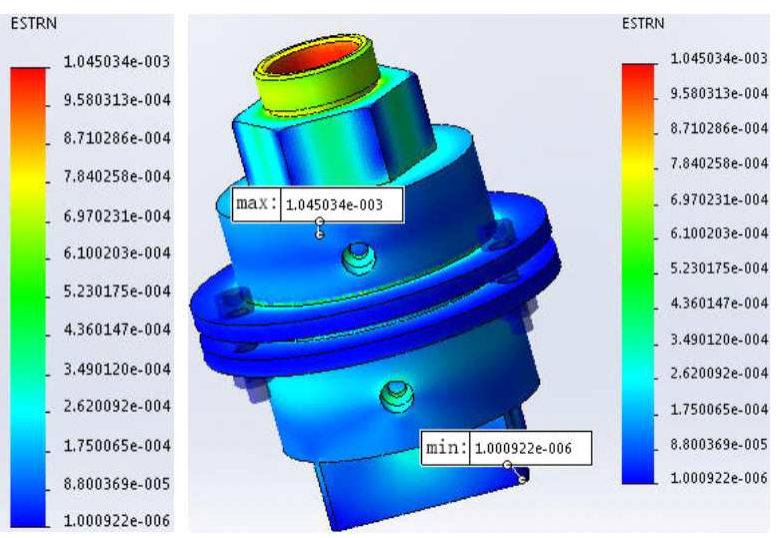

b) Top view

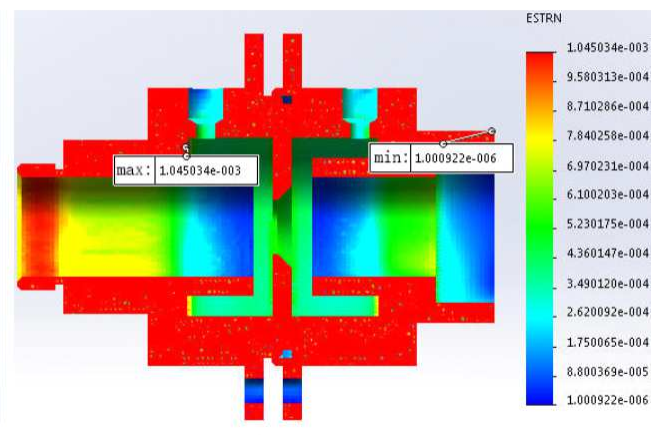

d) Cutaway view

Figure 15. Strain diagram $\left(20^{\circ} \mathrm{C}, 50 \mathrm{MPa}\right)$.

The temperature load on the inner wall of the orifice flowmeter pipeline is kept constant, and the pressure load is increased from $0.1 \mathrm{MPa}$ to $50 \mathrm{MPa}$. The results are shown in figure 15.

Figure 15 (a) is the main view of strain of the orifice flowmeter at $20^{\circ} \mathrm{C}, 50 \mathrm{MPa}$ and its detailed data; figure 15 (b) is the top view of strain of the orifice flowmeter at $20^{\circ} \mathrm{C}, 50$ $\mathrm{MPa}$ and its detailed data; figure 15 (c) is the left view of strain of the orifice flowmeter at $20^{\circ} \mathrm{C}, 50 \mathrm{MPa}$ and its detailed data; figure 15 (d) is the cutaway view of strain of the orifice flowmeter at $20^{\circ} \mathrm{C}, 50 \mathrm{MPa}$ and its detailed data.

Figures 15 (a) and figure 15 (d) show that the orifice plate flowmeter has the largest strain in its casing, the value is 0.001045034 , which is increased by 0.00097255983 when $20^{\circ} \mathrm{C}$ and $0.1 \mathrm{MPa}$ are applied to the inner wall of the orifice flowmeter pipeline, the strain at the exit is the smallest, the value is 0.000001000922 , which is increased by
0.0000010080087750 when $20^{\circ} \mathrm{C}$ and $0.1 \mathrm{MPa}$ are applied to the inner wall of the orifice flowmeter pipeline. Figure 15 (a) shows the maximum strain at the outlet of the orifice flowmeter is 0.0005230175 , the minimum is 0.000001000922 ; figure 15 (b) and figure 15 (c) show the maximum strain at the inlet of the orifice flowmeter is 0.0009580313 , the minimum is 0.0006100203 ; figure 15 (d) shows that the maximum strain of the inner wall at the pipeline of the orifice flowmeter is 0.0007840285 , and the minimum is 0.00008800369 . It can be seen that the orifice flowmeter has a temperature load of $20^{\circ} \mathrm{C}$ and remains unchanged, when the pressure load is increased from $0.1 \mathrm{MPa}$ to $50 \mathrm{MPa}$, the location of the maximum strain is basically unchanged, the value is increased by 0.00097255983 , and the location of minimum of strain is still obtained at the exit, and the value is increased by 0.000010080087750 . 


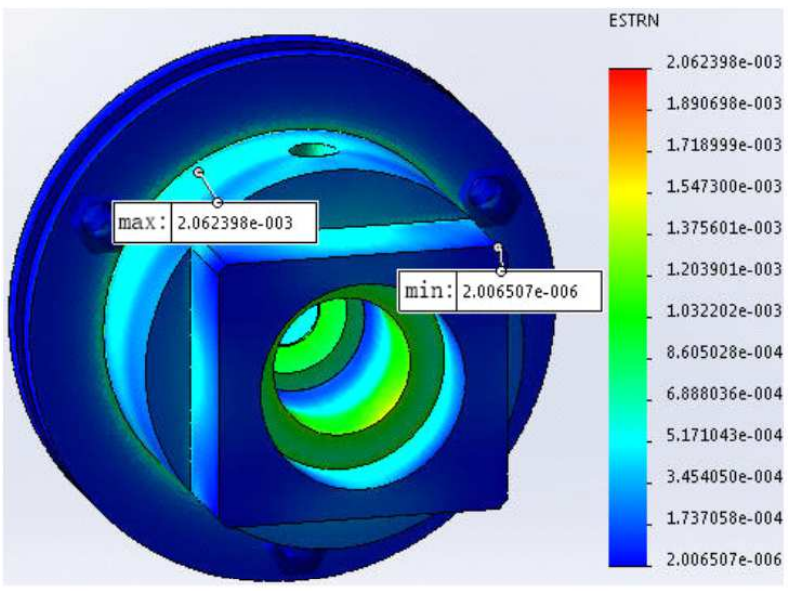

a) Main view

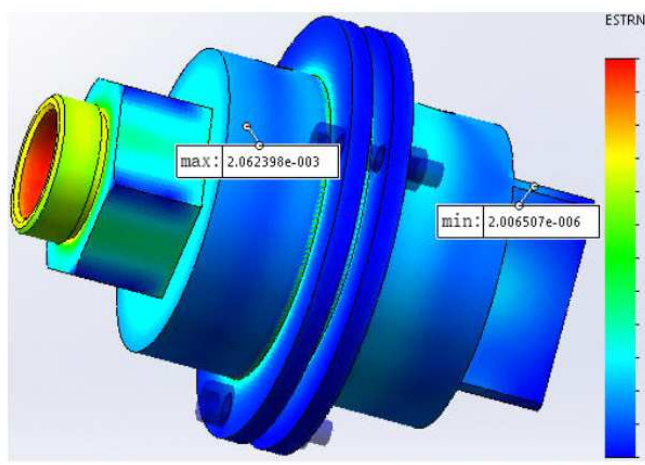

c) Left view

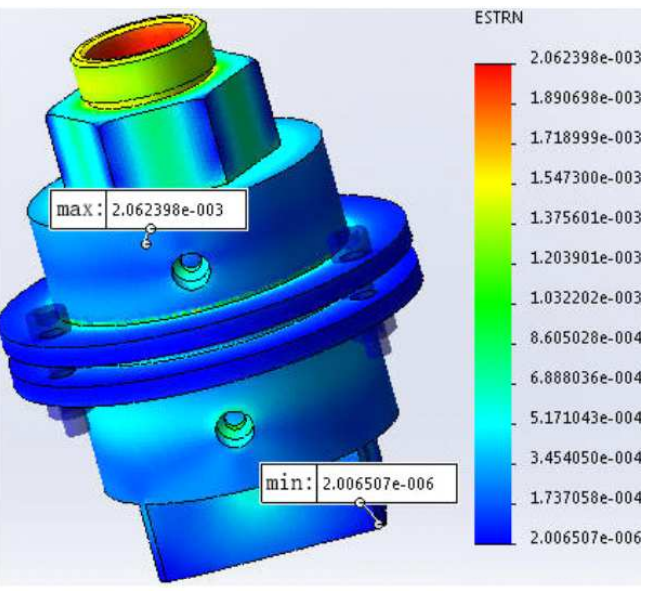

b) Top view

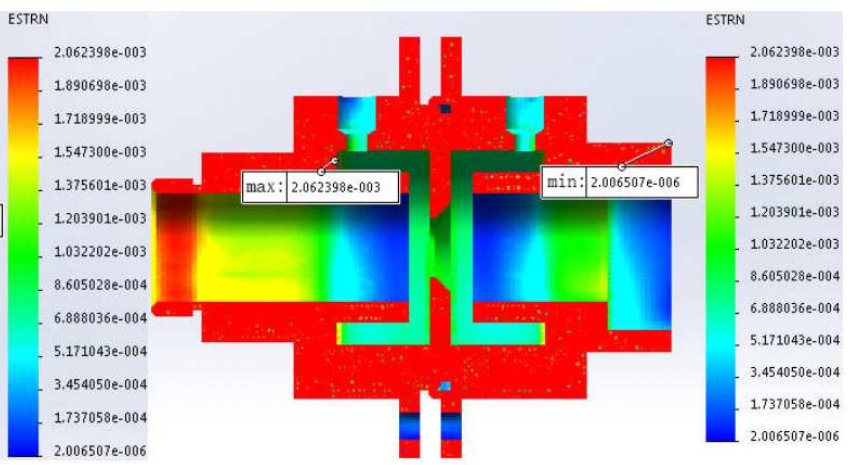

d) Cutaway view

Figure 16. Strain diagram $\left(20^{\circ} \mathrm{C}, 100 \mathrm{MPa}\right)$

The temperature load applied to the inner wall of the orifice flowmeter pipeline is kept constant, and the pressure load is increased from $50 \mathrm{MPa}$ to $100 \mathrm{MPa}$. The results are shown in figure 16 .

Figure $16(\mathrm{a})$ is the main view of strain of the orifice flowmeter at $20^{\circ} \mathrm{C}, 100 \mathrm{MPa}$ and its detailed data; figure $16(\mathrm{~b})$ is the top view of strain of the orifice flowmeter at $20^{\circ} \mathrm{C}, 100$ $\mathrm{MPa}$ and its detailed data; figure 16(c) is the left view of strain of the orifice flowmeter at $20^{\circ} \mathrm{C}, 100 \mathrm{MPa}$ and its detailed data; figure $16(\mathrm{~d})$ is the cutaway view of strain of the orifice flowmeter at $20^{\circ} \mathrm{C}, 100 \mathrm{MPa}$ and its detailed data.

Figures 16 (a) and figure 16 (c) show that the orifice plate flowmeter has the largest strain in its casing, the value is 0.002062398 , which is increased by 0.001017364 when $20^{\circ} \mathrm{C}$ and $50 \mathrm{MPa}$ are applied to the inner wall of the orifice flowmeter pipeline, the strain at the exit is the smallest, the value is 0.000002006507 , which is increased by 0.000001005585 when $20^{\circ} \mathrm{C}$ and $50 \mathrm{MPa}$ are applied to the inner wall of the orifice flowmeter pipeline. Figure 16 (a) shows the maximum strain at the outlet of the orifice flowmeter is 0.0008605028 , the minimum is 0.000002006507 ; figure 16 (b) and figure 16 (c) show the maximum strain at the inlet of the orifice flowmeter is 0.001890698 , the minimum is 0.001203901 ; figure 16 (d) shows that the maximum strain at the inner wall of the orifice flowmeter pipeline is 0.001547300 , and the minimum is 0.0001737058 . It can be seen that the orifice flowmeter has a temperature load of $20^{\circ} \mathrm{C}$ and remains unchanged, when the pressure load is increased from $50 \mathrm{MPa}$ to $100 \mathrm{MPa}$, the location of the maximum strain is basically unchanged, the value is increased by 0.001017364 , and the location of minimum of strain is also unchanged, and the value is increased by 0.000001005585 .

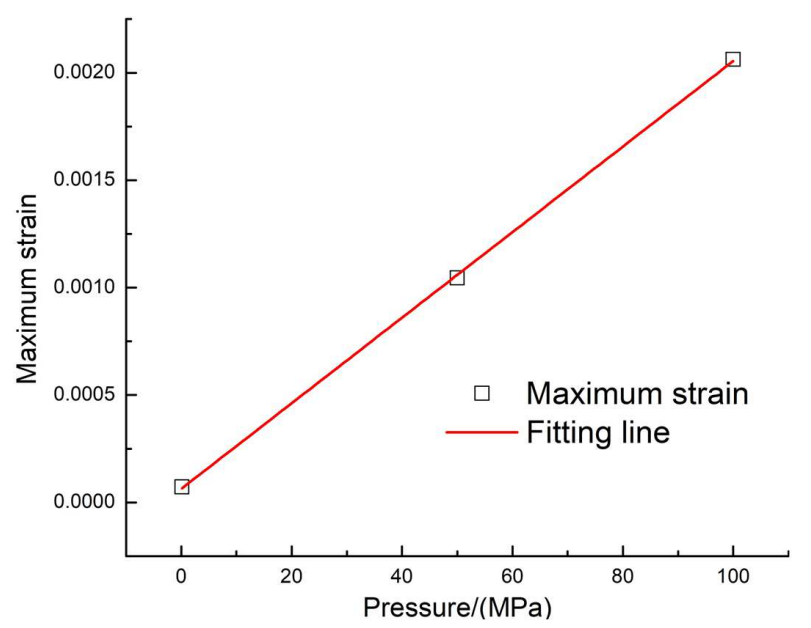

Figure 17. Diagram of relation between maximum strain and pressure at $20^{\circ} \mathrm{C}$.

From the comparison of the above data, we can see that: when the temperature load is $20^{\circ} \mathrm{C}$ and remains unchanged, the strain change of the orifice flowmeter is positively 
correlated with the change of the additional pressure load, and the maximum strain is also increased, as shown in figure 17. The strain value inside the orifice flowmeter casing is the maximum and the strain is minimum at the outlet. When the temperature load is $20^{\circ} \mathrm{C}$ and the pressure load is $0.1 \mathrm{MPa}$, the location of maximum of strain of the orifice flowmeter appears in the middle groove of the inner wall of the pipeline; when the temperature load is $20^{\circ} \mathrm{C}$ and the pressure load is 50 $\mathrm{MPa}$ or $100 \mathrm{MPa}$, the location of minimum of strain of the orifice flowmeter appears at the inlet.

\section{Conclusion}

In this paper, the three-dimensional model of the orifice flowmeter is analyzed by using simulation software. The relevant parameters are set, and the pressure load is regarded as the only variable. By observing the stress, strain and displacement variation of the three-dimensional model of the plate flow meter under different pressure load conditions, It was found that the maximum stress and maximum displacement of the orifice flowmeter under pressure load of $0.1 \mathrm{MPa}$ occur at the thinnest place of its plate, the maximum strain occurs at the middle groove of its pipeline; when the pressure load is $50 \mathrm{MPa}$ and $100 \mathrm{MPa}$, the maximum stress and maximum displacement of the orifice flowmeter occur at the inlet, and the maximum strain occurs inside the casing. The stress, displacement and strain of the orifice flowmeter are linearly related to pressure load. In the future design, the places where stress, strain and displacement are large should be strengthened to prolong the service life of the orifice flowmeter and ensure the accuracy of the orifice flowmeter.

\section{Acknowledgements}

The work was supported by Zhejiang Provincial Market Supervision and Administration Project (No. 20190131) and Quzhou Science and Technology Project (No. 2018K05).

\section{References}

[1] Pang Haiming. The method of improving the measuring accuracy of orifice flowmeter [J]. Chemical automation and instrument, 2018, 45 (12): 925-928.
[2] He Yunqi. Elementary discussion on factors affecting the accuracy of gas flow measurement by standard orifice flowmeter and corresponding measures $[\mathrm{J}]$. Measurement and testing technology, 2019, 46 (06): 73-75.

[3] Ma Yanjie, Wei Xinchen, Tang Gaofeng. Design and application of underground small orifice flowmeter [J]. Machine Tool and Hydraulic, 2018, 46 (10): 84-87.

[4] Zhao Wanxing, Zheng Wei, Wang Gang. Research and application of energy efficiency testing of differential pressure flowmeter [J]. metrology technology, 2016 (01): 28-29.

[5] Liu Haiying, Jiang Li, Liang Guangchao. Error analysis of natural gas flow measurement $[\mathrm{J}]$. Measurement and test technology, 2016, 43 (06): 52-53.

[6] Yang Fan. Error Analysis of Natural Gas Measurement [J]. Chemical Design Communication, 2018, 44 (07): 208.

[7] Sun Ning. Study on the factors influencing the error of differential pressure orifice flowmeter [J]. Management and Technology of Small and Medium-sized Enterprises (Late issue), 2019 (07): 153-154.

[8] Zheng Boren. Measurement error of orifice flowmeter and its causes and solutions $[\mathrm{J}]$. Chemical Design Communication, 2017, 43 (12): 112.

[9] Yang Jinghua, Bu Xing Qi. Problems and solutions in the measurement of natural gas flowmeter [J]. petrochemical technology, 2018, 25 (03): 28.

[10] Li Ting. Trial analysis and correction of the orifice flowmeter error [J]. Chemical Management, 2018, (28): 77-78.

[11] Chen Ying. Cause Analysis and Correction of the orifice flowmeter Error [J]. New Technologies and Products of China, 2016, (05): 31.

[12] Yang Gulati, Li Mingxia. Simulation of flow field inside orifice flowmeter [J]. Gansu Science Journal, 2015, 27 (06): 79-81, 106.

[13] He Liufang. Three-dimensional technology discussion based on SolidWorks software [J]. Southern Agricultural Machinery, 2018, 49 (21): 135, 137.

[14] Chen Yongdang, Bao Zhiqiang, Ren Huijuan. Finite element analysis of product design based on SolidWorks simulation [J]. Computer technology and development, 2012, 22 (09): 177-180. 